\title{
LETHAL AND NONLETHAL PREDATOR EFFECTS ON AN HERBIVORE GUILD MEDIATED BY SYSTEM PRODUCTIVITY
}

\author{
EARl E. Werner ${ }^{1,4}$ AND SCOTT D. PEACOR ${ }^{2,3}$ \\ ${ }^{1}$ Department of Ecology and Evolutionary Biology, University of Michigan, Ann Arbor, Michigan 48109 USA \\ ${ }^{2}$ Department of Fisheries and Wildlife, Michigan State University, East Lansing, Michigan 48824 USA \\ ${ }^{3}$ NOAA Great Lakes Environmental Research Laboratory, 2205 Commonwealth Boulevard, \\ Ann Arbor, Michigan 48105 USA
}

\begin{abstract}
Indirect effects propagated through intervening species in a food web have important effects on community properties. Traditionally, these indirect effects have been conceptualized as mediated through density changes of the intervening species, but it is becoming increasingly apparent that those mediated through trait (phenotypic) responses also can be very important. Because density- and trait-mediated indirect effects have different properties, it is critical that we understand the mechanisms of transmission in order to predict how they will interact, and when or where they will be important.

In this study, we examined the mechanisms and consequences of the lethal (densitymediated) and nonlethal (trait-mediated) effects of a larval odonate predator on a guild of four herbivore species (a larval anuran and three species of snails) and their resources. We also manipulated system productivity in order to explore the effects of environmental context on the transmission of these two types of indirect effects. We show that traitmediated effects arising from the predator can be very strong relative to density-mediated effects on both the competing herbivores and the species composition and production of their resources. A number of these indirect effects are shown to be contingent on productivity of the system. We further present evidence that trait- and density-mediated indirect effects originating from a predator may be transmitted independently through different routes in a food web, particularly when spatial responses of the transmitting prey are involved. Finally, effects on prey growth due to trait responses to the predator varied from negative to positive in predictable ways as a function of time and indirect effects on the larger food web. These results indicate the important role that trait-mediated indirect effects can play in trophic cascades and keystone predator interactions, and we discuss how the mechanisms involved can be incorporated in theory.
\end{abstract}

Key words: anuran larvae; food web; indirect effects; nonlethal effect; periphyton; predator; snails; trait-mediated effects; trophic cascades.

\section{INTRODUCTION}

The indirect effects propagated through intervening species to others in a food web are one of the defining aspects of ecological communities, and understanding the consequences of these indirect effects to community properties remains a major challenge to ecological theory (e.g., Polis and Winemiller 1996). Embracing the sheer complexity of ecological communities is a major aspect of this challenge (e.g., Yodzis 1996), but it is also clear that our understanding of the mechanisms of transmission of indirect effects is limited. Moreover, species can transmit different types of indirect effects, which may involve unique mechanisms and have different consequences to community dynamics (e.g., Abrams et al. 1996).

Traditionally, indirect effects have been conceptualized as occurring through density changes of the intervening species (i.e., density-mediated indirect in-

Manuscript received 21 January 2005; revised 17 June 2005; accepted 1 August 2005. Corresponding Editor: B. Downes.

${ }^{4}$ E-mail: eewerner@umich.edu teractions, hereafter DMIIs). However, indirect effects arising from other mechanisms also can be important, especially those transmitted through phenotypic responses of intervening species (i.e., trait-mediated indirect interactions, hereafter TMIIs) (Abrams 1995, reviewed in Werner and Peacor 2003). It is becoming increasingly apparent that the latter may often be as important as DMIIs in some systems (Turner and Mittelbach 1990, Huang and Sih 1991, Peacor and Werner 2001, 2004a, b. Schmitz et al. 2004). Moreover, such phenotypic (in many cases adaptive) responses are a major source of nonlinearity in the growth of species' populations (e.g., predator density can have strongly nonlinear effects on the interaction strength between a prey and its resource), which can lead to large and often nonintuitive effects on community structure and dynamics (Ives and Dobson 1987, Abrams 1992, reviewed in Bolker et al. 2003). Consequently, it is critical that we understand how these different types of indirect effects will interact and when or where they will be important. 
In this study, we examined the mechanisms and consequences of the lethal (density) and nonlethal (trait) effects of a predator in a simple food web embedded in systems of different productivity. Our motivation was to examine the interaction and relative importance of these two impacts of a predator on food web structure and the performance of the transmitting prey species, and to test for predicted context dependence of these impacts as resource productivity of the system varied (e.g., Peacor and Werner 2004a). We employed a system consisting of a larval odonate predator, a larval anuran prey as the focal transmitting species, and competing herbivore guild members composed of three species of snails. We show that TMIIs arising from the predator were very strong relative to DMIIs on the competing herbivores and on the species composition and standing crops of their periphyton resources. TMIIs thus contributed strongly to tropic cascades and potential keystone predator effects in this system. A number of these predator effects were highly contingent on productivity of the system, and it was necessary to consider both the predator-induced changes in consumer foraging rates and differential use of resource types in order to understand the interactions between lethal and nonlethal effects of the predator. We further present evidence that TMIIs and DMIIs originating from a predator may be transmitted independently through different routes in a food web. Finally, we show that the consequences of phenotypic responses to growth of the focal or transmitting prey species can vary dramatically depending on the balance of direct negative and indirect positive mechanisms associated with these responses. We discuss the conceptual import of these types of interactions to theory on food web interactions.

\section{Methods}

We manipulated the lethal and nonlethal effects of the odonate predator, Anax sp., and nutrient levels to assess impacts through a focal transmitting species, larvae of the green frog (Rana clamitans), to periphyton resources and three herbivorous snail species. We employed a $2 \times 2 \times 3$ factorial design with two levels of cue of predator presence (present and absent); two levels of tank productivity (high and low nutrients); and three tadpole density treatments, including absence, presence, and presence with removal, mimicking the lethal effect of the predator. Thus, the removal plus (nonlethal) predator treatment represents the impact of an "actual" predator, i.e., its net effect, and we can use the separate removal (density) and predator (trait) treatments to interpret the components of the net effect. We included the treatment without tadpoles to assess the impact of the tadpoles on resources and the other herbivores in the system. All 12 treatments were replicated in four spatial blocks.

Experiments were conducted in cylindrical cattle watering tanks $1.9 \mathrm{~m}$ in diameter and $0.75 \mathrm{~m}$ tall. Tanks were filled with $1300 \mathrm{~L}$ of well water and covered with
$60 \%$ shade cloth to deter colonization by aquatic insects and amphibians. Each tank received four small predator cages constructed from slotted plastic drainpipe $(11 \mathrm{~cm}$ in diameter, $10.5 \mathrm{~cm}$ long) with ends enclosed by fiberglass window screening. A small piece of polystyrene was placed in the cages to ensure that the cages floated near the surface. Dry oak leaves (Quercus sp., $300 \mathrm{~g}$ ) were added to each tank for physical complexity and as a substrate for resources.

We isolated the nonlethal effect of the predator by manipulating the presence of caged larval Anax (availability dictated the use of both $A$. junius and A. longipes which were always used in the same ratio in all tanks). Treatments consisted of either four caged Anax per tank or empty cages. Anax were fed three to five small green frog tadpoles (chosen so that the total mass equaled approximately $340 \mathrm{mg}$ ) as a food source every other day, and Anax were replaced (with the same species) if they did not feed. Numerous experiments have demonstrated that small tadpoles react to the presence of Anax by reducing foraging activity and spending more time in the leaves on the bottom of the tanks due to chemical cues that diffuse out of the cages (Werner and Anholt 1996, Peacor and Werner 2001, Relyea 2001). Feeding Anax magnifies the chemical cue (e.g., Van Buskirk and Arioli 2002) to levels that more likely mimic conditions in the field and ensures survival of the Anax. Nutrients originating from the caged Anax do not contribute significantly to tank productivity and tadpole growth rates (S. D. Peacor, unpublished data), and hence do not confound our results.

The experiment was conducted using green frog tadpoles obtained from cultures initiated with several egg masses collected from the University of Michigan's E. S. George Reserve experimental ponds. The eggs were transferred to wading pools filled with well water and after hatching the tadpoles were fed Purina rabbit chow. Tadpoles were stocked at an initial density of 150 tadpoles/tank when $10-15 \mathrm{mg}$ in size. We isolated the lethal effect of the predator on the tadpoles (no cue of predator presence) by subjecting populations to removal on a schedule mimicking the decline in density over time caused by predation. We manually removed the tadpoles with small nets to give a $6 \%$ daily removal rate $(29,22,28,18,11$, and 7 tadpoles were removed on days $5,9,15,23,28$, and 37 , respectively). This rate was chosen to lead to a projected final reduction in density of $90 \%$, assuming survival of tadpoles not removed was $85 \%$ (a value we had observed in previous experiments). The exponential removal schedule, in which over half of the tadpoles were removed within the first two weeks of a nearly six-week experiment (and at shorter initial time intervals), was chosen in order to accentuate the density effect of the predator so that comparisons with the nonlethal effect would be conservative. On each occasion when tadpoles were removed, all other tanks were subjected to equivalent 
disturbance by swirling the nets in the tanks for a similar period of time.

Nutrients were added to the tanks to support periphyton growth, a principal resource for the experimental food web. We employed two nutrient levels; in the low nutrient treatments we initially added $15 \mathrm{mg} \mathrm{N} / \mathrm{d}$ (in the form of $\left.\mathrm{NH}_{4} \mathrm{NO}_{3}\right)$ and $2.7 \mathrm{mg} \mathrm{P} / \mathrm{d}\left(\mathrm{KH}_{2} \mathrm{PO}_{4}\right)$, giving a $13 \mathrm{~N}: 1 \mathrm{P}$ molar ratio. The high nutrient treatments consisted of 10 times this amount. Nutrients were added every two to four days. After 10 days we doubled these rates because periphyton growth appeared low.

In addition to the tadpole herbivores, the tank communities included three species of snails, Planorbella (= Helisoma) trivolvis, Physa gyrina, and Stagnicola elodes, whose densities were not manipulated. Snails were collected from local ponds on the E. S. George Reserve, and seven adults of each species introduced into each tank (with the exception of Physa, where six were introduced). All species reproduced in the tanks over the course of the experiment.

The tanks were filled with well water on 22-23 June 1998 , and the leaves along with an inoculum of phytoplankton, periphyton, and zooplankton from a local pond added the following day. In order to stimulate initial production, $6 \mathrm{~g}$ of rabbit chow, $150 \mathrm{mg}$ of nitrogen, and $27 \mathrm{mg}$ of phosphorous (13N:1P molar ratio) also were added at this time. Six days later on 29 June, the 150 small $(10-15 \mathrm{mg})$ green frog tadpoles were added to the tanks. The experimental treatments were initiated by adding one final-instar Anax to each of the four cages in tanks designated for the nonlethal predator treatment on 2 July (considered day 1 of the experiment). Snails also were added to the tanks on 2 July.

In order to follow the temporal trends in growth of the tadpoles, we sampled all tanks on day 15 and weighed tadpoles. We collected 28 individuals (the removal number on that date) from each tank, individually weighed them, and returned those from nonremoval treatments to their original tanks.

We conducted behavioral observations to assess tadpole activity on days 12 and 27 of the experiment; observations were made between 13:00 and 16:00 hours. We slowly circled each tank and recorded the number and activity of tadpoles on the sides of the tanks, and on an area of the bottom of the tanks cleared of leaves earlier for this purpose. Observations were repeated four times and the data for each tank averaged for each measurement period. Response variables analyzed were the percentage of the population on the sides of the tanks (number counted on the sides of the tanks divided by the estimated population size assuming all mortality occurred at the beginning of the experiment and accounting for all animals removed in the removal treatment), and percent of animals active (fraction of those counted both on the sides and bottoms of tanks that were moving or feeding).
To assess "habitat use" and responses of the snails we conducted counts of the adult snails on the sides of the tanks on four days early in the experiment $(10,13$, 14 , and $15 \mathrm{July}$, after which they were obscured by algal growth in some of the tanks). It was not feasible to count snails in the leaves on the bottoms of the tanks. Assuming no mortality, we could then compute the fraction of the adults on the sides of the tanks (thus any mortality biased counts in the direction of lower fractions on the sides). It was not possible to assess the distribution of newly hatched snails due to their small size and the fact that they were hidden by filamentous algae in some of the tanks.

Resources (periphyton) were sampled near the midpoint of the experiment (day 22) from black plastic strips cut from $0.15 \mathrm{~mm}$ plastic sheeting (see, e.g., Brönmark et al. 1992). Pairs of plastic strips $(18 \times 2.7$ $\mathrm{cm}$ ) were taped to the sides (in two groups separated by $20 \mathrm{~cm}$ ) and on the bottoms (two groups also separated by $20 \mathrm{~cm}$ ) of the northeast side of each tank. The strips on the bottoms were kept clear of leaves throughout the experiment. To collect samples for chlorophyll $a$ analysis, a $5.1-\mathrm{cm}$ section of a strip from each group on the bottoms (and similarly for the sides) was cut under water and slowly raised out of the tank. The two strips collected from the bottoms of each tank (and similarly those from the sides of the tanks) were combined, placed in aluminum foil envelopes, and frozen with dry ice. These samples were then transferred to a $-60^{\circ} \mathrm{C}$ freezer until later analysis. In the laboratory, the periphyton was removed from the strips with razor blades. Chlorophyll $a$ was extracted with $\mathrm{N}, \mathrm{N}-\mathrm{di}-$ methyl formamide and estimated using fluorometry (Strickland and Parsons 1972, Speziale et al. 1984).

To collect samples for periphyton cell counts and taxonomic composition, a 5.1-cm section of the plastic strips was carefully cut underwater and allowed to float up several centimeters into an inverted bottle filled with well water. Strips from adjacent groups on the sides of the tanks (and similarly those from the bottoms) were combined in one bottle and preserved with $0.35 \%$ gluteraldahyde (St. Amand 1990). In the laboratory, periphyton was carefully removed from the plastic strips with a razor blade in a manner that avoided clumping. Small clumps were manually separated, and then samples were diluted to $72 \mathrm{~mL}$ and sonicated for $10 \mathrm{~s}$ for further separation. Identifications were made with subsamples in a $0.086 \mathrm{~mL}$ Palmer-Maloney counting chamber at $400 \times$. Single transects of at least three subsamples were performed, which led to cell counts ranging from 140 to 3500 . While most cells were identified to genus, some diatoms were unidentifiable with this procedure. In previous studies, we have found that small diatoms respond differently to tadpole herbivory than large diatoms. For analyses, we grouped diatoms (both those that were and were not identifiable) into "small" and "large" diatoms if their length was smaller or larger than $20 \mu \mathrm{m}$, respectively. Because algal 
species counts were very time intensive, we only conducted counts for six treatments that enabled us to examine major trends determined from the chlorophyll $a$ analyses (see Results). We conducted counts for treatments with and without tadpoles at the two nutrient levels to examine the interaction between grazing and nutrient level. These were all samples from the sides of the tanks in the absence of Anax. In addition, we conducted counts for samples on the sides of the tanks from the two treatments with and without tadpoles in the presence of Anax at the high nutrient level.

The experiment was terminated on 11 August, 41 days after commencement of the treatments. Leaves were first removed from the tanks in small lots after shaking in the water column and then placed in buckets with water. Leaves in the buckets were examined for any remaining animals, but very few were recovered indicating that nearly all remained in the tanks. Tadpoles and snails were then collected with dip nets from the tanks, and the remaining water passed through a sieve to retain any animals that eluded the dip nets. Tadpoles were weighed and counted, and snails preserved in $70 \%$ alcohol for later analysis.

Snail size structure and dry mass were quantified by sieving the snails through a series of 12 sieves, ranging from 1 to $11.2 \mathrm{~mm}$. All snails passed through the largest mesh size, so there were 11 potential size classes (Planorbella was represented in all of these, Physa and Stagnicola only in the seven smallest size classes). We did not include snails that passed through the smallest mess size (because many in this size class were likely lost during collection, and they would not have contributed significantly to total biomass). Snails in each size class were counted, with the exception of some samples from small size classes which were subsampled due to high numbers (exceeding 1500 snails) and the total number calculated using the ratio of the mass of the subsample to the mass of all snails in the sample. Dry mass was determined for each size class by multiplying the number of snails by average dry mass of snails in that size class (determined from a sample of snails drawn from multiple tanks). Total biomass for a species was the sum of the dry mass of all size classes.

Statistical procedures.-One tank exhibited aberrant patterns in both tadpole and snail responses and preliminary analyses indicated that residuals from treatment means of this tank were always greater than three standard deviation units from the mean of all residuals. This tank was deleted from all subsequent analyses. Individual tadpole mass and cumulative tadpole production were tested with repeated-measures ANOVAs. Simple main effects were employed to explain withinsubject interactions. Tadpole behavioral responses were tested with repeated-measures MANOVA, snail biomass with MANOVA, and periphyton chlorophyll $a$ with an ANOVA. After determining that a given multivariate test was significant, we examined how each dependent variable contributed to the results using in- dividual between-subjects tests. In the case of both snail biomass and periphyton analyses, tests indicated no significant effect of tadpole removal on responses. Therefore, the two tadpole treatments (removal and nonremoval) were combined to examine the effect of tadpole presence on these variables. Periphyton species counts were analyzed with two separate models because of the missing cells in treatments comparisons. We grouped algae for analysis into four taxonomic/ physiognomic groups, bluegreens (predominantly Anabaena sp.), greens (predominantly Stigeoclonium sp. and Oedogonium sp.), large diatoms (predominantly Synedra sp. and Gomphonema sp.), and small diatoms (predominantly Achnanthes sp.) The first analysis was a two-way MANOVA crossing presence of tadpoles with nutrient levels to examine the effects of these factors and their interaction on algal counts, and the second a two-way MANOVA examining the effects of presence of tadpoles and predators at the high nutrient level. In each case we again examined how each dependent variable contributed to the results using individual between-subjects tests. All data were checked for normality with Lilliefors test and homogeneity of variances with Levene's test and ln transformed where necessary. When block effects were not significant we dropped block from the model.

\section{RESULTS}

\section{Tadpole responses}

Survivorship.-There were no significant effects of any treatment on survivorship of the tadpoles. Survivorship in the nonremoval treatments averaged $0.96 \pm$ 0.01 (mean $\pm \mathrm{SE}$ ). Considering removed tadpoles survivors, survivorship in the removal treatments averaged $0.97 \pm 0.01$; actual "survivorship" (i.e., percentage of introduced tadpoles present at the end of the experiment) in the removal treatments averaged $0.21 \pm 0.005$. Thus, tadpole survival in the removal treatment was somewhat higher than our target of $10 \%$.

Individual growth.-Removal and nutrients had large main effects on tadpole size (Fig. 1, Table 1, between-subjects tests). At the end of the experiment, tadpoles were nearly twofold larger in the high compared to low nutrient treatments, as well as in the removal compared to the nonremoval treatments. The effect of predator presence on tadpole size differed over time (Fig. 1), and this time dependence was influenced by tadpole removal (Table 1, day by predator by removal interaction) and nutrient level (Table 1, day by predator by nutrient interaction). Early in the experiment (on day 15), predator cue had a negative effect on tadpole size at the high, but not at the low, nutrient level (simple main effects; high nutrient level, $F_{1,23}=$ 8.6, $P=0.007$; low nutrient level, $F_{1,23}=0.4, P=$ $0.5)$. Thus, growth suppression due to predator cue was greater at higher growth rates (Fig. 1), i.e., there was a direct correlation between the magnitude of the Anax 


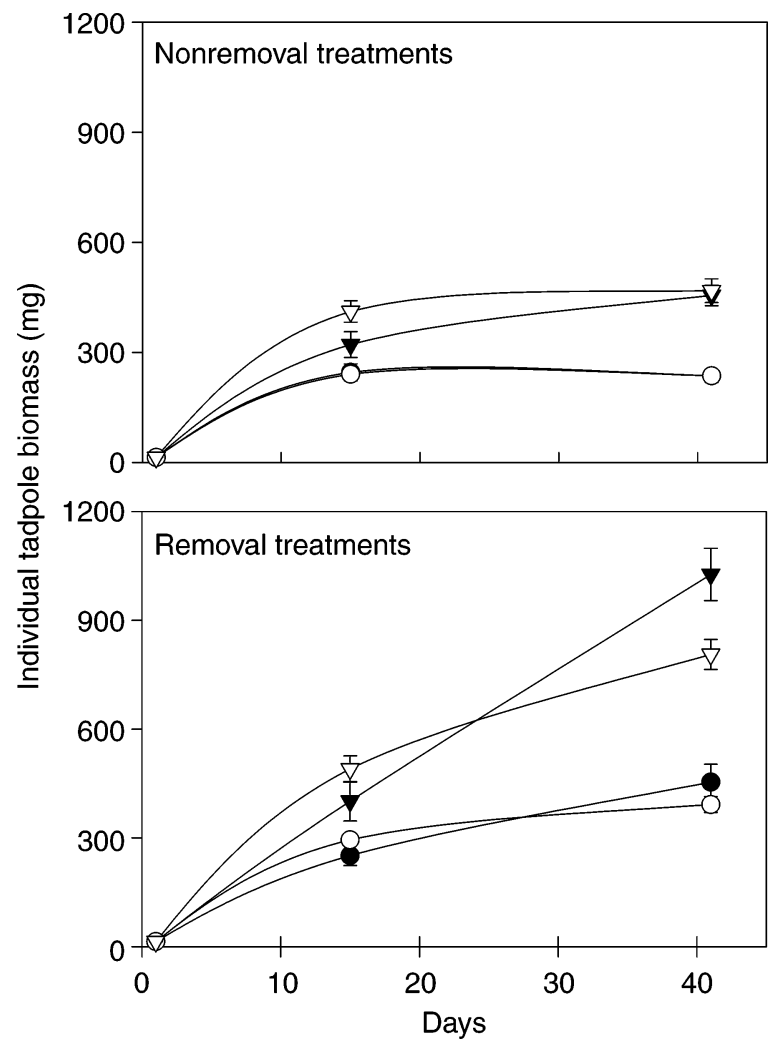

FIG. 1. Individual mass (mean $\pm \mathrm{SE}$ ) of tadpoles through time in the different experimental treatments. Open symbols are in the absence of the caged predator, and solid symbols are in the presence of the caged predator. Inverted triangles are high-nutrient treatments, and circles are low-nutrient treatments. The nonremoval treatment (upper panel) and the removal treatment (lower panel) are shown. Lines are smoothed curves drawn through the three points and are meant only as a guide for the eye. effect on size and the size of the tadpoles on day 15 (though with only four points this relationship was marginally nonsignificant; $r=0.85, F_{1,2}=11.02, P=$ $0.08)$. On day 41 , predator presence had a positive effect on tadpole size in the removal treatments but no effect in the nonremoval treatments (simple main effects, removal treatments, $F_{1,23}=15, P=0.001$; nonremoval treatments, $F_{1,23}=0.4, P=0.5$ ).

Total production.- Since tadpole mortality was very low, cumulative tadpole production in the nonremoval treatments simply paralleled individual growth (Fig. 2). However, in the removal treatment nearly $80 \%$ of the tadpoles were removed, but at different sizes over time. Therefore, we calculated total production for these treatments assuming that all nonremoval mortality occurred at the beginning of the experiment and adding in the biomass of individuals removed when they were removed. The new information revealed by this analysis was that the day by removal interaction was significant $\left(F_{2,46}=14, P \ll 0.001\right)$ indicating that, by day 41 , removal had a positive effect on production (Fig. 2 , simple main effects, $\left.F_{1,23}=31, P \ll 0.001\right)$ that did not occur on day 15 (simple main effects, $F_{1,23}=0.3$, $P=0.6)$.

Behavior.-Presence of the predator had strong effects on the behavior of tadpoles (Fig. 3; repeatedmeasures MANOVA, between-subjects effect, $F_{2,19}=$ $67, P \ll 0.001)$. Presence of the predator markedly reduced the percent of tadpoles on the sides of the tanks (univariate between-subjects test, $F_{1,20}=107, P \ll$ 0.001 ) and caused large reductions in activity of these tadpoles (univariate between-subjects test, $F_{1,20}=56$, $P \ll 0.001)$. These behavioral responses to the predator were very strong on both observational dates, indicating little or no habituation to cue of predator presence (Fig. 3).

\section{Snail responses}

Biomass. - Snail responses were realized through reproduction and the subsequent growth of these cohorts.

TABLE 1. Repeated-measures ANOVA of individual tadpole mass.

\begin{tabular}{lrrr}
\hline \hline \multicolumn{1}{c}{ Variable } & \multicolumn{1}{c}{ MS } & \multicolumn{1}{c}{$F$} & \multicolumn{1}{c}{$P$} \\
\hline Within-subjects effects $(\mathrm{df}=2,44)$ & & & \\
Day & 2007813 & 634.1 & $<0.001$ \\
Day $\times$ predator & 29612 & 9.4 & $<0.001$ \\
Day $\times$ removal & 234295 & 74.0 & $<0.001$ \\
Day $\times$ nutrient $\times$ removal & 260061 & 82.1 & $<0.001$ \\
Day $\times$ predator $\times$ remutrient & 17157 & 5.4 & 0.009 \\
Day $\times$ predator $\times$ no & 10332 & 3.3 & 0.049 \\
Day $\times$ removal $\times$ nutrient & 40431 & 12.8 & $<0.001$ \\
Day $\times$ predator $\times$ removal $\times$ nutrient & 3864 & 1.2 & 0.304 \\
Between-subjects effects $($ df $=1,23)$ & & & \\
Intercept & 7496257 & 3321.3 & $<0.001$ \\
Predator & 433 & 0.2 & 0.666 \\
Removal & 359543 & 159.3 & $<0.001$ \\
Nutrient & 659307 & 292.1 & $<0.001$ \\
Predator $\times$ removal & 9805 & 4.3 & 0.048 \\
Predator $\times$ nutrient & 5 & 0.0 & 0.963 \\
Removal $\times$ nutrient & 64554 & 28.6 & $<0.001$ \\
Predator $\times$ removal $\times$ nutrient & 7858 & 3.5 & 0.075 \\
\hline
\end{tabular}




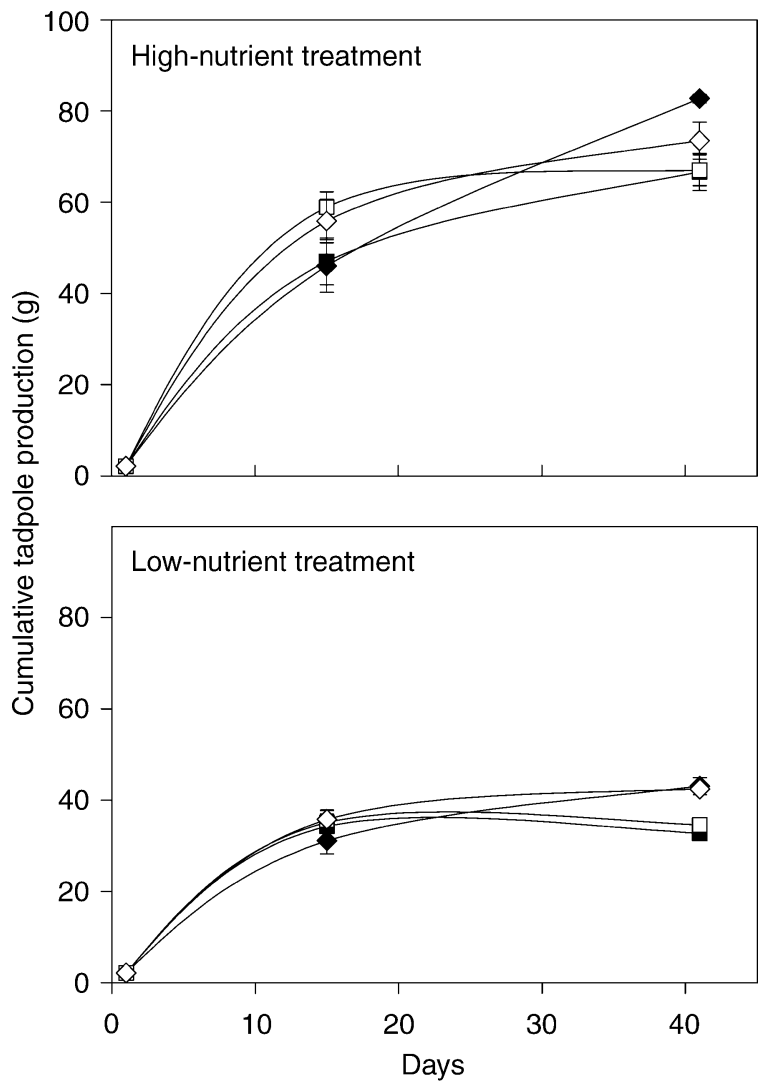

FIG. 2. Cumulative production (mean $\pm \mathrm{SE}$ ) of tadpole populations through time for high nutrient (upper panel) and low nutrient (lower panel) treatments. Diamonds are the removal treatments, and squares are the nonremoval treatments. Open symbols are in the absence of the caged predator, and solid symbols are in the presence of the caged predator. Lines are smoothed curves drawn through the three points, meant only as a guide for the eye.

MANOVA indicated that, overall, presence of tadpoles, predator cue, and nutrient level all significantly affected snail biomass (Table 2a). All interaction effects also were quite strong (Table 2a), in large part due to differences in individual species' responses. First consider responses of Physa and Stagnicola, which were generally parallel. Both species responded significantly to nutrient level (Table 2c, d); total biomass of Physa was 2.8-fold, and Stagnicola 2.2-fold, higher at the higher nutrient level (Fig. 4). Both species also exhibited significant reductions in biomass in the presence of Anax (Fig. 4, Table 2c, d). These were direct responses to cue of predator presence, not indirect effects through tadpoles or resources, as evidenced by the fact that biomass of both species was reduced to 0.73 of that in Anax's absence in the no tadpole treatment (Fig. 4, simple main effects; Physa, $F_{1,39}=12, P=0.001$; Stagnicola, $\left.F_{1,39}=7, P=0.01\right)$. Finally, both species also were negatively affected by the presence of tadpoles (Fig. 4, Table 2c, d). The magnitude of this (presumably competitive) effect of tadpoles was greater on
Stagnicola (across all treatments biomass 0.43 of that in the absence of tadpoles) than on Physa (biomass 0.77 of that in absence of tadpoles). The tadpole removal treatment had no effect on either species (Fig. 4).

Planorbella also responded positively to nutrients (biomass was 4.3-fold higher at the high nutrient level, Table 2b), but its responses to other treatments differed markedly from Physa and Stagnicola. There was no negative (competitive) effect of tadpoles on Planorbella; in fact, at the high nutrient level there was a trend for presence of tadpoles to have a positive or facilatory effect on Planorbella biomass (Fig. 4, simple main effect marginally nonsignificant, $F_{1,39}=3.3, P=$ 0.079). In addition, Planorbella did not respond directly to the presence of the predator; biomass was equivalent across predator treatments in the absence of tadpoles (Fig. 4). However, when tadpoles were present there was a significant negative effect of Anax on Planorbella biomass at the high nutrient level (Table 2b; simple main effects, $F_{1,39}=21, P<0.001$; see Fig. 4). These results indicated that the effect of predator cue on Planorbella was transmitted indirectly through the tadpoles.

Snail distributions. - The only factor that affected adult snail distributions was the presence of tadpoles (MANOVA with all species, $F_{6,62}=3.5, P=0.004$ ). A greater proportion of adult snails was found on the
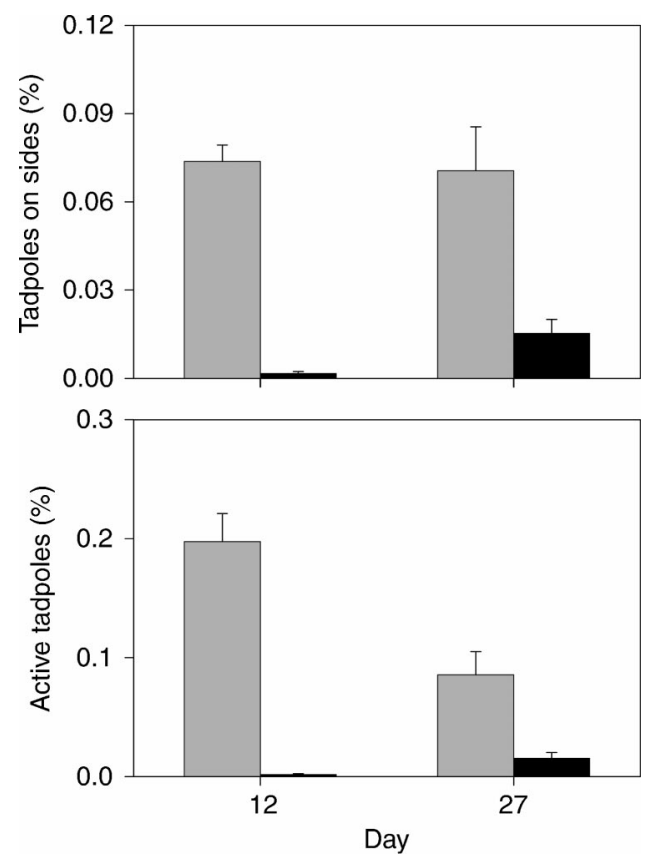

FIG. 3. Behavioral responses of the tadpoles to the presence of caged Anax on the two dates when observations were made. The top panel is the percentage of individuals observed on the sides of the tanks, and the bottom panel is the percentage of individuals observed on the sides that were active. Black histogram bars are in the presence of Anax, and gray histogram bars are in its absence. 
TABLE 2. MANOVA of total biomass of snails.

\begin{tabular}{|c|c|c|c|}
\hline Variable & $\mathrm{df}$ & $F$ & $P$ \\
\hline \multicolumn{4}{|l|}{ a) Total snail biomass } \\
\hline Intercept & 3,37 & 377.2 & $<0.001$ \\
\hline Tadpole & 3,37 & 28.0 & $<0.001$ \\
\hline Predator & 3,37 & 6.9 & 0.001 \\
\hline Nutrient & 3,37 & 82.7 & $<0.001$ \\
\hline Tadpole $\times$ predator & 3,37 & 5.9 & 0.002 \\
\hline Tadpole $\times$ nutrient & 3,37 & 7.1 & 0.001 \\
\hline Predator $\times$ nutrient & 3,37 & 2.6 & 0.065 \\
\hline Tadpole $\times$ predator $\times$ nutrient & 3,37 & 2.7 & 0.061 \\
\hline Variable & MS & $F$ & $P$ \\
\hline \multicolumn{4}{|l|}{ b) Planorbella $(\mathrm{df}=1,39) \dagger$} \\
\hline Intercept & 1646771636 & 132 & $<0.001$ \\
\hline Tadpole & 13627460 & 1.1 & 0.303 \\
\hline Predator & 31769336 & 2.5 & 0.119 \\
\hline Nutrient & 593900378 & 47 & $<0.001$ \\
\hline Tadpole $\times$ predator & 64217379 & 5.1 & 0.029 \\
\hline Tadpole $\times$ nutrient & 29136757 & 2.3 & 0.135 \\
\hline Predator $\times$ nutrient & 42114300 & 3.4 & 0.074 \\
\hline Tadpole $\times$ predator $\times$ nutrient & 24658802 & 2 & 0.180 \\
\hline \multicolumn{4}{|l|}{ c) Stagnicola $(\mathrm{df}=1,39) \dagger$} \\
\hline Intercept & 35348080 & 296 & $<0.001$ \\
\hline Tadpole & 5731453 & 48 & $<0.001$ \\
\hline Predator & 750711 & 6.3 & 0.016 \\
\hline Nutrient & 5236446 & 44 & $<0.001$ \\
\hline Tadpole $\times$ predator & 251875 & 2.9 & 0.094 \\
\hline Tadpole $\times$ nutrient & 960711 & 8.1 & 0.007 \\
\hline Predator $\times$ nutrient & 425825 & 3.6 & 0.066 \\
\hline Tadpole $\times$ predator $\times$ nutrient & 66475 & 0.6 & 0.459 \\
\hline \multicolumn{4}{|l|}{ d) Physa (df $=1,39) \dagger$} \\
\hline Intercept & 4797758584 & 1039 & $<0.001$ \\
\hline Tadpole & 73460628 & 16 & $<0.001$ \\
\hline Predator & 84541151 & 18 & $<0.001$ \\
\hline Nutrient & 1061370117 & 230 & $<0.001$ \\
\hline Tadpole $\times$ predator & 9229887 & 2 & 0.165 \\
\hline Tadpole $\times$ nutrient & 11020021 & 2 & 0.130 \\
\hline Predator $\times$ nutrient & 23008812 & 5 & 0.031 \\
\hline Tadpole $\times$ predator $\times$ nutrient & 1349470 & 0.3 & 0.592 \\
\hline
\end{tabular}

Note: The model was reduced to examine the effects of tadpole presence after determining that removal had no effect (see Fig. 4).

$\dagger$ Between-subjects effects.

sides of the tanks in the presence of tadpoles (proportion on sides in absence/presence of tadpoles for Planorbella was $0.43 / 0.53$, for Stagnicola was $0.35 / 0.52$, and for Physa was 0.50/0.59). Though all species exhibited this trend, the between-subjects tests indicated that it was significant only in the case of Stagnicola. These values are likely underestimates of the numbers on the sides because any individuals dead or missed due to visibility problems would be assessed as on the bottom. Virtually all egg masses were deposited on the sides of the tanks and qualitative observations suggested that the great majority of the small snails recruited to the populations were on the sides of the tanks as well.

\section{Periphyton responses}

Chlorophyll a responses.-As expected, there was a strong main effect of nutrient level on periphyton as measured by chlorophyll $a$ levels (Table 3 ). Significant interactions between tadpole presence and nutrients, and predator presence and nutrients, indicated that tadpoles and predator cue affected chlorophyll $a$, but that these effects were a function of nutrient level (Table 3 ). Tadpoles reduced chlorophyll $a$ at the low nutrient level by $65 \%$ ( 68 bottom, 62 sides), whereas they increased chlorophyll $a$ levels by twofold at the high nutrient level (1.8 bottom, 2.3 sides) (Fig. 5, Table 3, between-subjects tests, significant tadpole by nutrient interactions for both bottom and side). Further, on the sides of the tanks there was a strong interaction between nutrient level and presence of Anax (Fig. 5, Table 3 , between-subjects test for side); at the high nutrient level presence of Anax caused a sharp drop in chlorophyll $a$ to $60 \%$ of its level in the absence of the predator (simple main effect, $F_{1,39}=6.1, P=0.02$ ). In contrast, there was no effect of Anax at the low nutrient level or on the bottoms of the tanks (Fig. 5, Table 3). That is, presence of Anax negated the positive 

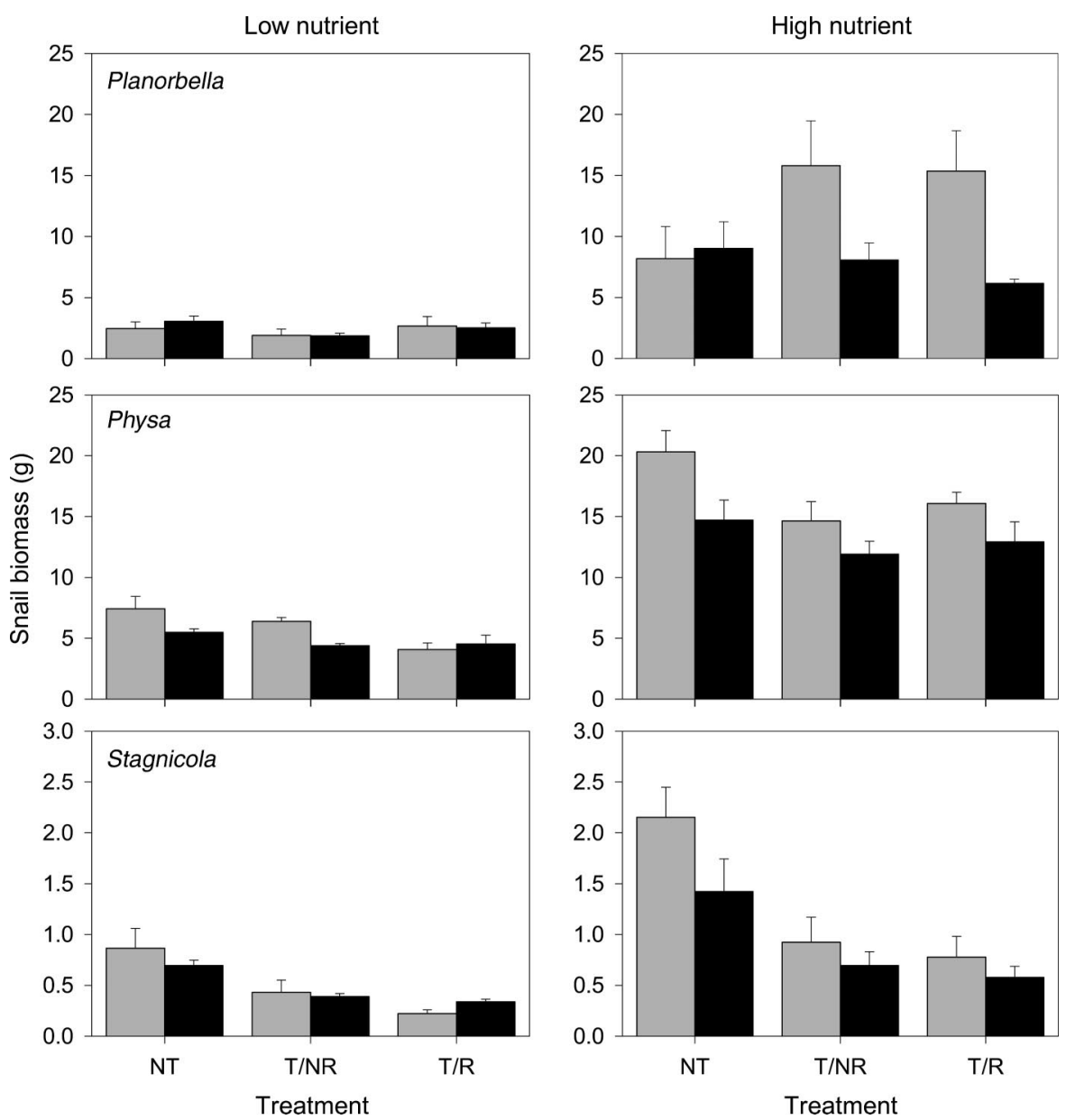

FIG. 4. Dry biomass (mean $+\mathrm{SE}$ ) of snail populations (three species) at the end of the experiment at two nutrient levels. Black histogram bars are in the presence of Anax, and gray histogram bars are in its absence. Treatments were: NT, no tadpoles; T/NR, tadpoles with no removal; and T/R, tadpoles with removal.

effect of tadpoles on periphyton at the high nutrient level on the sides, but not on the bottoms, of the tanks. In the absence of tadpoles, neither nutrient addition nor presence of Anax had any effect on chlorophyll $a$ levels, and chlorophyll $a$ densities were similar on the bottoms and sides of the tanks (Fig. 5).

Species responses. - The chlorophyll $a$ analyses revealed two strong but perplexing trends: (1) tadpoles reduced periphyton at low nutrient levels but increased it at high nutrient levels and (2) presence of Anax reduced the positive effect of tadpoles on periphyton at high nutrient levels on the sides of the tanks. We examined species composition of the periphyton for relevant treatments (see Methods) to interpret these results. Analyses aggregating species into four physiognomic/taxonomic groups; bluegreen algae, green algae, and large and small diatoms; indicated that tadpoles significantly affected taxonomic group counts (gray bars in Fig. 6, MANOVA, $F_{4,6}=4.6, P=0.05$ ). Tadpoles reduced large diatoms (between subjects test, $\left.F_{1,9}=5.2, P=0.05\right)$, but positively affected green algae (Fig. 6; between subjects test, $F_{1,9}=11.3, P=$ 0.008). Tadpole effects on small diatoms exhibited a trend for reduction at low nutrients but facilitation at high nutrients (Fig. 6; between subjects test, nutrient by tadpole interaction, $F_{1,9}=23, P=0.001$ ). Tadpoles had no effect on bluegreen algae.

The consistent pattern in these data was the opposing effects of tadpoles on large diatoms and green algae, which were the larger and dominant components of the periphyton. To understand how these effects led to diametrically opposed chlorophyll $a$ responses to tadpoles at the two nutrient levels required further examination of the species composition of the green algae. At low nutrient levels, Stigeoclonium responded positively to tadpoles, and, at high nutrient levels, this species plus Oedogonium responded positively. The positive effect of tadpoles on periphyton chlorophyll $a$ at the high nutrient level appeared to be due essentially to the response of Oedogonium (Fig. 7). In the absence of tadpoles, neither nutrients nor predator presence had any effect on Oedogonium, but, in the presence of tad- 
TABLE 3. MANOVA of chlorophyll $a$ data.

\begin{tabular}{|c|c|c|c|}
\hline MANOVA variable & df & $F$ & $P$ \\
\hline Intercept & 2,38 & 88.30 & $<0.001$ \\
\hline Tadpole & 2,38 & 2.18 & 0.127 \\
\hline Predator & 2,38 & 1.82 & 0.176 \\
\hline Nutrient & 2,38 & 18.25 & $<0.001$ \\
\hline Tadpole $\times$ predator & 2,38 & 1.40 & 0.258 \\
\hline Tadpole $\times$ nutrient & 2,38 & 14.19 & $<0.001$ \\
\hline Predator $\times$ nutrient & 2,38 & 3.29 & 0.048 \\
\hline Tadpole $\times$ predator $\times$ nutrient & 2,38 & 2.24 & 0.120 \\
\hline Between-subjects effects variable & MS & $F$ & $P$ \\
\hline \multicolumn{4}{|l|}{ Bottom $(\mathrm{df}=1,39)$} \\
\hline Intercept & 1433237 & 72.59 & $<0.001$ \\
\hline Tadpole & 8218 & 0.42 & 0.523 \\
\hline Predator & 5311 & 0.27 & 0.607 \\
\hline Nutrient & 336951 & 17.06 & $<0.001$ \\
\hline Tadpole $\times$ predator & 2562 & 0.13 & 0.721 \\
\hline Tadpole $\times$ nutrient & 164836 & 8.35 & 0.006 \\
\hline Predator $\times$ nutrient & 4473 & 0.23 & 0.637 \\
\hline Tadpole $\times$ predator $\times$ nutrient & 509 & 0.03 & 0.873 \\
\hline \multicolumn{4}{|l|}{ Side $(\mathrm{df}=1,39)$} \\
\hline Intercept & 1981437 & 171 & $<0.001$ \\
\hline Tadpole & 50660 & 4.38 & 0.043 \\
\hline Predator & 24355 & 2.11 & 0.155 \\
\hline Nutrient & 397636 & 34.38 & $<0.001$ \\
\hline Tadpole $\times$ predator & 20679 & 1.79 & 0.189 \\
\hline Tadpole $\times$ nutrient & 332387 & 28.73 & $<0.001$ \\
\hline Predator $\times$ nutrient & 50622 & 4.38 & 0.043 \\
\hline Tadpole $\times$ predator $\times$ nutrient & 46071 & 4.0 & 0.053 \\
\hline
\end{tabular}

Note: The model was reduced to examine the effects of tadpole presence after determining that removal had no effect (see Fig. 5).
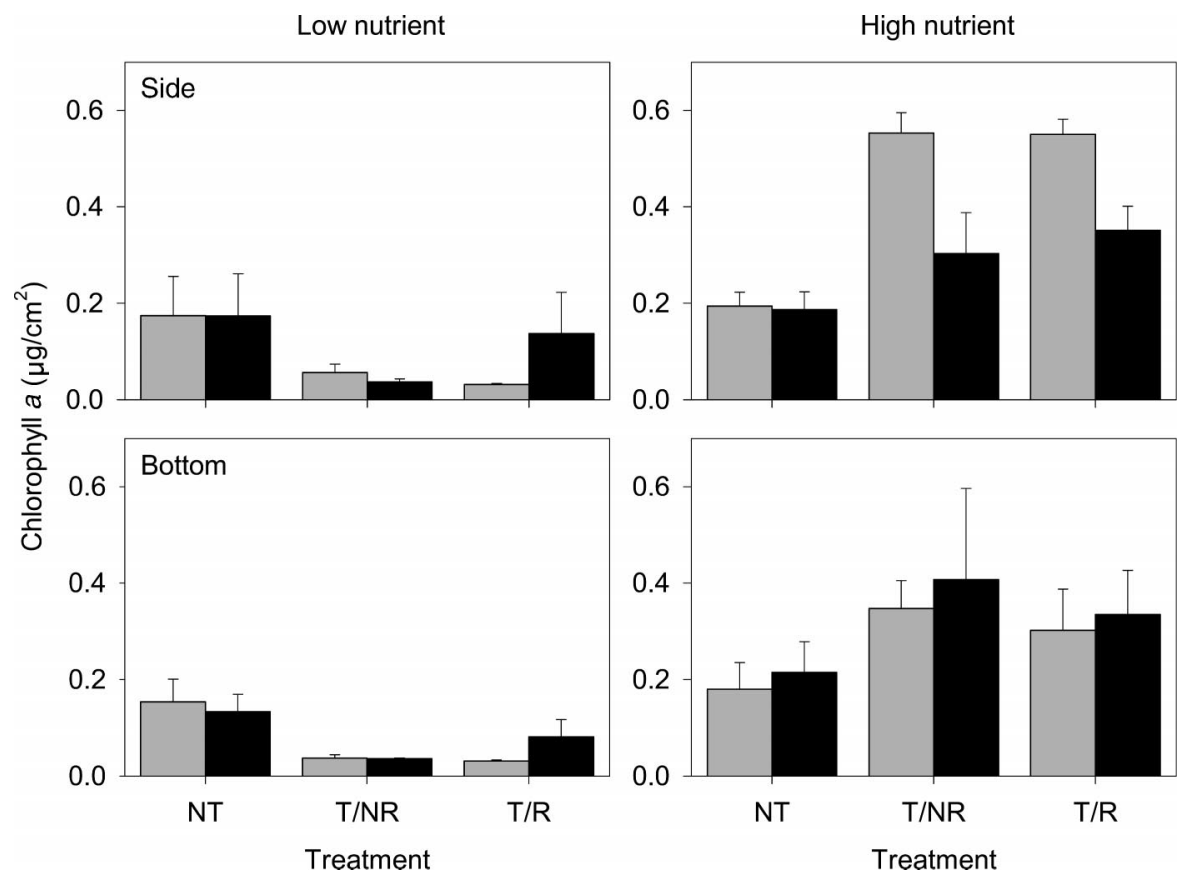

FIG. 5. Periphyton chlorophyll $a$ densities (mean + SE) on the sides (top panels) and bottoms (bottom panels) of the tanks at low and high nutrient levels. Black histogram bars are in the presence of Anax, and gray histogram bars are in its absence. Treatments were: NT, no tadpoles; T/NR, tadpoles with no removal; and T/R, tadpoles with removal. 

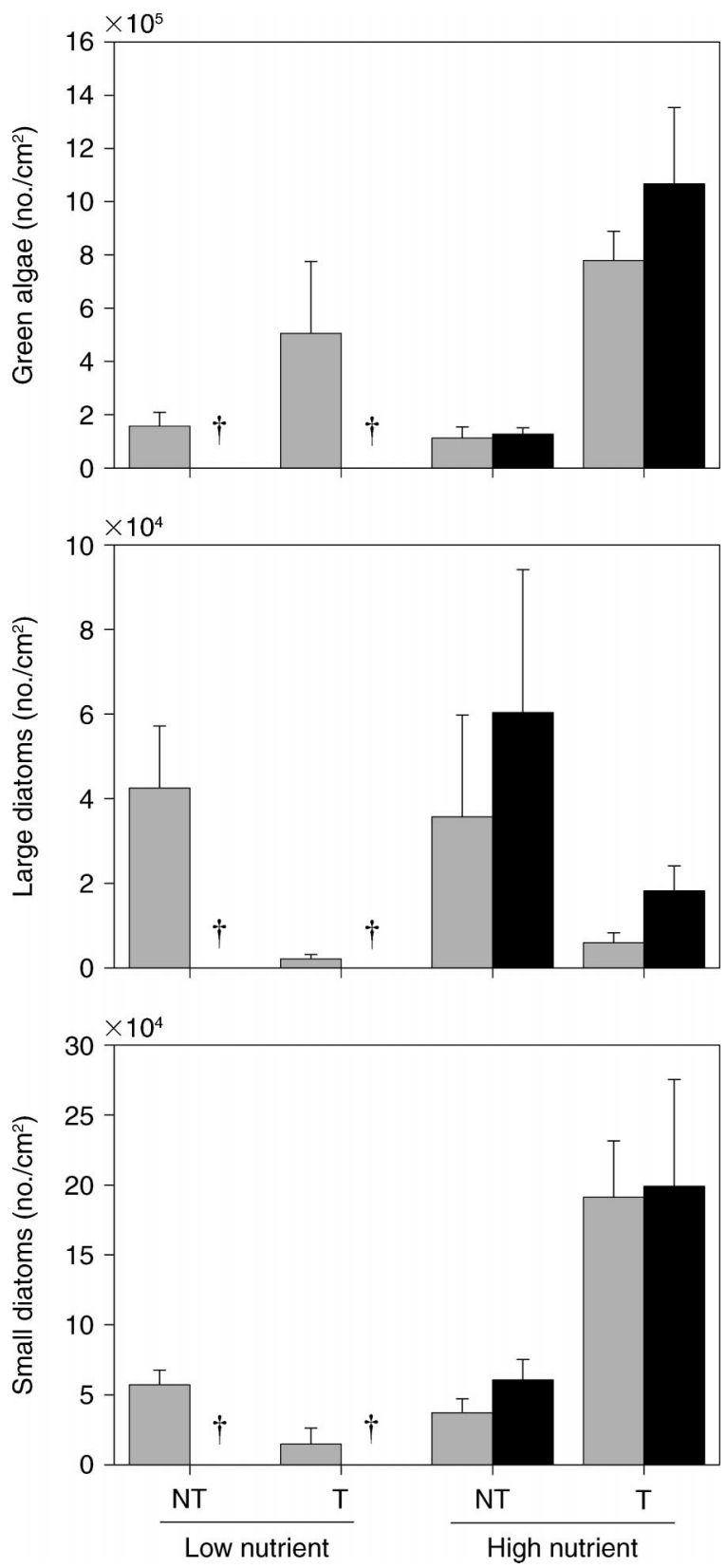

FIG. 6. Transect counts (mean $+\mathrm{SE}$ ) of periphyton species groups (green algae, large and small diatoms) on the sides of the tanks for the six treatment combinations counted. Black histogram bars are in the presence of Anax, and gray histogram bars are in its absence. Treatments were: NT, no tadpoles; T, tadpoles, at the two nutrient levels. Daggers indicate predator treatments that were not counted at the low-nutrient level.

poles, Oedogonium was 29 -fold more abundant at the high nutrient level. The species of Oedogonium represented in our system were characterized by very large cell biovolumes (E. Werner, unpublished data), apparently causing the increase in chlorophyll $a$ at the high nutrient level.
There was no predator effect on the aggregate periphyton species counts (compare gray and black bars in Fig. 6), despite the fact that at the high nutrient level predator presence had a large negative effect on chlorophyll $a$ (Fig. 5). Again, this apparent contradiction was due to Oedogonium responses. Presence of the predator largely negated the strong positive effect of tadpoles on Oedogonium on the sides, reducing their abundance to $26 \%$ of that in the absence of the predator (Fig. 7), thus resulting in the effect of predator presence on chlorophyll $a$ levels (Fig. 5).

\section{DISCUSSION}

This experiment demonstrates an array of important direct and indirect effects of a predator in a simple food web due to its impacts on density, and on traits (behavior), of a transmitting prey species. We have shown that the magnitude, and in some cases the sign, of these effects were contingent on potential productivity of the system in which they were imbedded. In overview, the results demonstrated (1) that the trait effects of the predator were very strong and, in fact, often stronger than the density effects, both on the focal prey species and other species indirectly affected by the predator through the focal prey species; (2) that system productivity influenced the indirect effects arising from both the density and trait effects of the predator; (3) that similar effects of the predator on different species were due to completely different mechanisms; and (4) that DMIIs and TMIIs were independently transmitted through different routes in the food web. To explore these results, we first discuss the impact of the predator on the green frog tadpoles (focal trans-

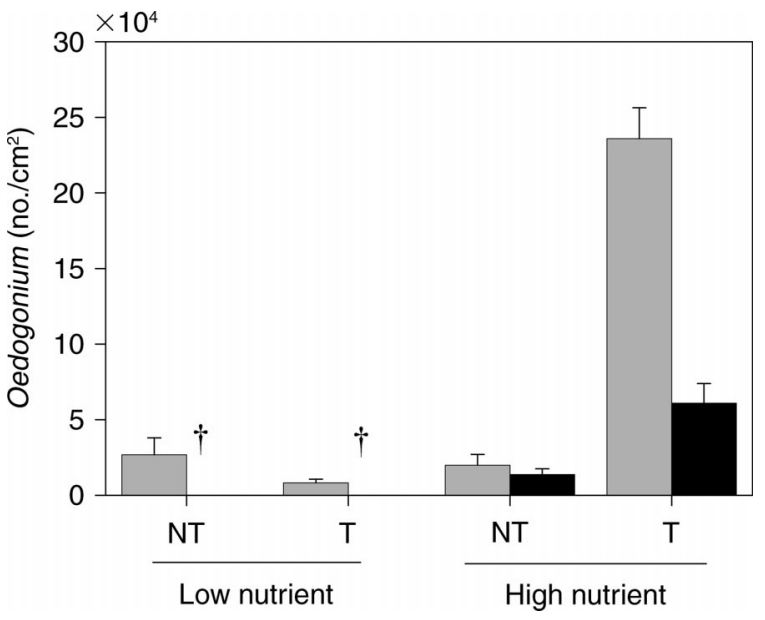

FIG. 7. Transect counts (mean + SE) of Oedogonium on the sides of the tanks for the six treatment combinations counted. Black histogram bars are in the presence of Anax, and gray histogram bars are in its absence. Treatments were: NT, no tadpoles; T, tadpoles, at the two nutrient levels. Daggers indicate predator treatments that were not counted at the low-nutrient level. 
mitting species) and then the subsequent indirect effects to the other food web components.

\section{Interaction of density (lethal) and trait (nonlethal) predator effects and nutrients on tadpole growth}

There was remarkable variation in growth of the green frog tadpoles with respect to nonlethal predator presence and nutrient level (Fig. 1). Anax induced strong trait responses in the tadpoles; tadpoles reduced activity and time on the sides of the tanks in its presence (Fig. 3), both of which should reduce resource uptake and therefore growth of the tadpoles (Werner and Anholt 1993, Relyea and Werner 1999, Van Buskirk 2000). The behavioral responses to Anax remained strong throughout the experiment (Fig. 3), consistent with numerous other studies that have indicated tadpoles do not habituate to the presence of the predator. Therefore, the variation in tadpole growth illustrated in Fig. 1 was not due to variation in the behavioral responses to Anax over time.

The patterns in tadpole growth can be understood by considering the negative and positive effects of predator presence. First, the predator has a direct negative effect on tadpole growth through induction of reduced foraging rates. Accordingly, if resources are not limiting, the response to the predator should lead to a reduction in growth rate proportional to the reduction in foraging rate (see Peacor and Werner 2004a, Turner 2004). Consistent with this expectation, we found primarily negative effects of predator presence early in the experiment when resources were higher and growth rates faster (i.e., resource limitation less, Fig. 1); in fact, the magnitude of the growth reduction in the presence of Anax was positively correlated with tadpole growth rate (see also Werner and Anholt 1996, Van Buskirk and Yurewicz 1998, Turner 2004).

However, predator-induced trait responses not only have direct negative effects on resource uptake, but also have positive indirect effects reflected back to the focal species through resource dynamics (Peacor and Werner 2000, 2004a, Turner 2004). These positive indirect effects become important as resources become limiting and can counterbalance the direct negative effects. The first of these positive effects results from the fact that the predator also induces a reduction in the rate that conspecifics forage, i.e., reduces intraspecific competition for resources. Thus, the direct negative effect of the predator will be reduced as competition increases (e.g., over time as resources are depleted, or at high compared to low densities of conspecifics). This positive effect apparently had counterbalanced the direct negative effect of the predator by day 15 in the low nutrient/nonremoval treatment where resources would be depleted first, and by the end of the experiment in the high nutrient/nonremoval treatment, even though on day 15 the tadpoles in the predator treatment were only $78 \%$ of the size of those in the no-predator treatment (Fig. 1). In the two removal treatments complete balancing clearly happened somewhere between days 15 and 41 (Fig. 1). Peacor and Werner (2004a) present a model and further empirical examples of this process (e.g., see also Werner and Anholt 1996, Van Buskirk and Yurewicz 1998, Peacor 2002, Relyea 2004).

The second positive influence of predator presence can arise through indirect effects on resource productivity. Resource production is generally nonlinearly (convexly) related to standing crop; i.e., an increase in resources at low resource levels leads to an increase in growth potential, whereas an increase at high resource levels leads to an increase in self-limitation. Thus, the predator can have an indirect positive effect on resource levels/productivity by reducing foraging rates of the prey when resources are strongly depleted, and the scope of this rebound effect will be a function of nutrient levels in the environment (e.g., Noy-Meir 1975, Abrams 1992, Peacor 2002, Peacor and Werner 2004a, Turner 2004). In this case, there can be a net positive growth response of the tadpoles to presence of the predators, e.g., in the removal treatments the direct negative effects of the predator on day 15 were overbalanced by the positive effects by day 41 (Fig. 1, see also Peacor 2002). It is not clear why the positive response only occurred in the removal and not the nonremoval treatments. The strength of the effects may have been influenced by the interaction with lethal (removal) effects.

How do these nonlethal effects of the predator interact with its lethal effects? Predatory removal of individuals will positively affect individual prey growth rate by freeing resources (e.g., Wilbur 1987). If density effects of the predator are small, we can approximate its net effect on prey growth rate using the analysis of trait effects detailed above (see Peacor and Werner $2004 a$ ). However, because the trait effects of the predator on prey growth are dependent on prey density (net attack rate of the prey population on resources), increasing lethal effects of the predator can change their expression. For example, in the absence of high predation rates the net effect of the predator on prey growth may be positive. But as its lethal effects increase, the net attack rate of the prey population will be lowered (i.e., resources will be less limiting), and the nonlethal predator effect becomes primarily negative. In this case, the trait and density effects operate synergistically to negatively affect prey population growth rate through reductions in density and individual growth rate (see Peacor and Werner 2000). However, at high net attack rates of the focal prey population on resources, predatory removal and induced reductions in foraging activity can combine to reduce overexploitation of resources and positively affect individual growth rate.

These conclusions were supported by the cumulative production estimates. Total tadpole production was $18 \%$ higher (averaged across all other treatments) in the removal compared to the nonremoval treatments. 


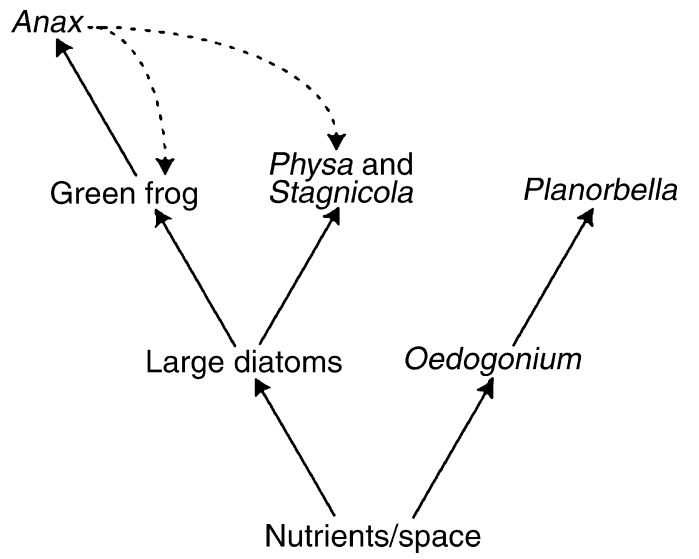

FIG. 8. Major components of the experimental food web as determined from the results. Solid lines represent potential consumptive (density) effects, and dashed lines represent trait effects. Lines from Anax were experimentally manipulated.

In the removal treatments at the low nutrient level, there was no difference in production in the nonlethal presence and absence of the predator and thus removal of individuals (the DMII) apparently was the major cause of this increased production. In contrast, in the removal treatments at the high nutrient level where scope of periphyton response was greater, removal alone enhanced production by $10 \%$ over nonremoval treatments, but adding the nonlethal presence of the predator increased production to $24 \%$ over nonremoval treatments (see Fig. 2). Thus, the presence of the predator had a large positive trait-mediated indirect effect on production synergistically with the density effect. As in this experiment, in natural systems all of the above mechanisms can operate simultaneously, and therefore it is critical to be aware of the opposing mechanisms in order to predict net predator effects as environmental conditions change over space and time. These mechanisms are readily incorporated into simple and general models of trophic interactions (e.g., Bolker et al. 2003, Peacor and Werner 2004a, b).

\section{Indirect effects of Anax through tadpoles on other food web components}

The above mechanisms provide context for interpreting the indirect effects of Anax through green frogs on periphyton resources and then to the snails (the relevant aspects of the food web for this experiment are presented in Fig. 8). Tadpoles had strong impacts on the overall abundance and species composition of the periphyton, and consequently the latter also was impacted by cue of predator presence. Tadpoles reduced periphyton (chlorophyll $a$ ) standing crops at the low nutrient level, whereas they facilitated periphyton standing crops at the high nutrient level (Fig. 5). At both nutrient levels they altered species composition, favoring green algae over large diatoms due to selective grazing of large diatoms (predominantly Synedra and
Gomphonema sp.). This pattern is consistent with observations that green frog gut contents are dominated by diatoms (Jenssen 1967) and the importance of diatoms to tadpole performance (Kupferberg et al. 1994). Apparently, selective grazing of large diatoms removed dominant competitors (or species that can attach to and shade green algal species) and enabled the more grazing resistant green algae to dominate. The differential responses of the two dominant green alga genera (Stigeoclonium and Oedogonium) appeared to be responsible for the fact that periphyton abundance effects were diametrically opposed at the two nutrient levels.

Stigeoclonium (a prostrate colonial green) responded positively to tadpole grazing at both nutrient levels, and has been shown in other studies to be a poor competitor but resistant to grazing (McCormick and Stevenson 1991, Rosemond 1996, Steinman 1996). Oedogonium responded positively to tadpole grazing only at the high nutrient level (Fig. 7); Oedogonium is a tall overstory filamentous green with basal holdfasts also reported to be facilitated by green frog tadpole grazing in lakes (Graham and Vinebrooke 1998, see also Dudley 1992, Sarnelle et al. 1993). Because of its extremely large cell biovolumes (E. Werner, unpublished data), Oedogonium appears to account for the opposing effects of tadpoles on chlorophyll $a$ responses. It is also likely that the response of the small diatoms to tadpole presence (negative at low, and positive at high, nutrient levels) was related to the responses of Oedogonium, as overstory development may provide a relative refuge for small understory forms. For example, in our experiment, Achnanthes (a short-stalked adnate diatom) responded negatively to tadpole grazing at low nutrient levels but positively at high nutrient levels where Oedogonium was abundant (see also Sarnelle et al. 1993).

The periphyton responses further point to the impact of tadpole behavioral responses to Anax. Algal responses on the bottoms and sides of the tanks were parallel except that the positive effect of tadpoles on periphyton chlorophyll $a$ ( $\sim$ Oedogonium abundance) was negated on the sides in the presence of the predator (Figs. 5 and 7). Presence of the predator markedly reduced the number of tadpoles on the sides of the tanks (Fig. 3), and this response by tadpoles was apparently sufficient to then negate their positive impact on the periphyton on the sides. The absence of a predator effect on chlorophyll $a$ levels on the bottoms was due to the fact that tadpoles continued to forage there in the presence of the predator. There was no effect of "predatory" removal of tadpoles on the periphyton in any treatment. Thus, the (negative) cascading effect of predator presence on periphyton standing crops on the sides was entirely a TMII, which has important implications to where the impact of density- vs. trait-mediated effects occur in food webs.

The indirect effects of Anax on periphyton (through tadpoles) had significant ramifications to snail performance (Fig. 8). These ramifications are most clearly 
seen in the responses of Planorbella, which was the only snail species where indirect effects of Anax were unconfounded by direct responses; Planorbella did not respond directly to presence of Anax (see responses in the absence of tadpoles, Fig. 4). Further, Planorbella was not affected negatively (through competition) by tadpoles (e.g., see the low nutrient level, Fig. 4), and tadpoles actually had a strong facilitory effect on Planorbella at the high nutrient level. This positive effect was negated by presence of Anax, i.e., by suppressing tadpole presence and activity on the sides of the tanks, Anax inhibited the facilitory effect of tadpoles on periphyton there and then to Planorbella. It is not clear why Planorbella was the only snail species positively affected by tadpoles through responses of Oedogonium. Perhaps Planorbella was able to utilize the Oedogonium directly, or was better able to forage on the small diatoms facilitated by Oedogonium. Chase et al. (2001) show that Planorbella is a relative "digger," i.e., capable of reducing periphyton to lower levels than Physella (= Physa) and a lymneaid species (as is Stagnicola). This may explain why both Physa and Stagnicola were affected by competition from tadpoles, whereas Planorbella exhibited no negative effects.

The impact of Anax on Physa and Stagnicola was a composite of direct and indirect effects. Physa and Stagnicola were both negatively affected by presence of Anax, and indirectly affected by competition from tadpoles (Fig. 4). We would expect, then, that effects of Anax presence on tadpoles would indirectly positively benefit the snails (i.e., reduce the competitive impact of tadpoles, Fig. 8). The results indicated, however, that the net effect of Anax presence was largely still negative on these species, and therefore that the positive indirect effect through tadpoles did not overbalance the negative direct effect.

Presence of Anax had a negative effect on the total biomass of all three snail species at the high nutrient levels. However, it is clear from other treatments that these negative effects were due to completely different mechanisms; in the case of Physa and Stagnicola to the direct negative effect of the presence of the predator, and in the case of Planorbella to the negation of the positive indirect effect through tadpoles (Fig. 8). These results underscore the critical need to understand mechanisms in interpreting food web interactions and caution against considering species responding in similar ways as functionally equivalent or redundant in a system.

There are several general lessons that emerge from this study. First, comparisons of the relative magnitudes of the indirect effects arising from the lethal and nonlethal impacts of Anax though tadpoles on periphyton and snails indicated that the TMIIs were often stronger than the DMIIs. In our experiment, the removal plus (nonlethal) predator treatment represents the impact of the "actual" predator, i.e., its net effect. The separate removal and predator treatments represent independent manipulations of the density and traits effects, and we can use these to interpret the components of the net effect. When we do this we find that that the density component was small relative to the trait effect. For example, removal (DMII) had no effect on either periphyton or the snails under any conditions (e.g., Figs. 4 and 5). In contrast, presence of chemical cues of Anax presence had strong indirect effects (TMIIs) on both periphyton and Planorbella on the sides of the tanks. Thus, the TMIIs dominated the net effect of the predator despite the fact that tadpole density was reduced to $20 \%$ of the original population over the course of the experiment. This result is not an experimental artifact resulting from an exaggerated nonlethal effect of the predator. The behavioral response of tadpoles induced by four caged Anax is on the same order of magnitude as two free Anax in the tanks, and two free Anax have a similar effect on tadpole density as our removal manipulation (Peacor and Werner 2001). We have outlined the general reasons why TMIIs may be large relative to DMIIs elsewhere (Peacor and Werner 2000, 2001, 2004a). These results indicate the potentially important role of TMIIs in trophic cascade and keystone predator effects.

However, both TMIIs and DMIIs (reflected back through resources) had prominent effects on the tadpoles. The TMIIs were large as discussed earlier, and the DMIIs led to a twofold increase in size of tadpoles in the system (Fig. 1). Why were both types of indirect effects transmitted to the tadpoles and only the TMII to the periphyton and Planobella? There are several nonexclusive hypotheses for this result. First, if resources are limiting (as in our experiment) a reduction in tadpole density may have little effect on their (net foraging) impact on resources and subsequently on snails. Tadpoles forage a much larger area per unit time than snails, and any reduction in tadpole density that released resources would therefore have a larger positive effect on the remaining tadpoles than on snails. Consequently, the DMII on the tadpoles would appear as increased growth of tadpoles, but would be less apparent on the snails. Further, the increase in size of the remaining tadpoles could compensate in terms of foraging rates for the tadpoles removed (larger individuals forage at faster rates). Both of these effects could result in competition from tadpoles being effectively similar from the perspective of the snails in the different treatments.

Second, DMIIs and TMIIs originating from a predator may be transmitted through different links in the food web depending on the trait affected. The necessary condition for a DMII to be experienced by a competitor of the focal (reacting) species is that it feed on the same set of resources; i.e., removal of the focal species results in an increase in available resources. Consequently, the DMII necessarily will be localized to the area used by the focal prey in the presence of the predator. When the predator induces a spatial or habitat shift 
by the focal prey, the TMII can be transmitted to competitors in areas that the focal prey has vacated. If the competitors predominantly use the habitat vacated, then they experience only the TMII from the predator and not the DMII.

In this experiment, tadpoles largely shifted off the sides of the tanks in the presence of Anax (Fig. 3), and therefore tadpoles competing intraspecifically for resources on the bottoms would experience both TMIIs and DMIIs from the predator. However, since a large fraction of the snail population was found on the sides of the tanks (and there also was a significant shift at least by adult snails to the sides in the presence of tadpoles), snails on the sides would be affected only by the TMII caused by the habitat shift of the tadpoles. Snails on the sides would experience little impact of the reduction in density of tadpoles (DMII) on resources, which would be localized to the bottom habitat. Spatial or habitat shifts by prey in the presence of predators are very common (e.g., Lima 1998), and lead to strong TMIIs (Werner and Peacor 2003). Thus, many species may experience only the TMIIs from predators, i.e., TMIIs and DMIIs often may be transmitted through different routes in the food web. Similarly, this effect could be very important at the landscape scale when ovipositing adults avoid habitats in response to presence of certain predators, e.g., as shown in aquatic insects and amphibians (Resetarits 2001, Rieger et al. 2004). This potential effect of predators, which extends to species or habitat regions where density effects, or even activity, of the predator are usually not evident, has been virtually ignored in the predator-prey literature. That is, the influence of predators on communities may be consistently of greater scope than typically assumed.

In conclusion, TMIIs can play a large and varied role in ecological food webs. In our experiment, indirect effects due to the predator were primarily due to trait changes in the transmitting species. Moreover, these indirect effects were contingent on ecological context (e.g., nutrient levels in the environment) in straightforward ways that can be incorporated in simple and general ecological models (e.g., see Peacor and Werner $2004 a, b)$. Hopefully, these insights and models will be useful in interpreting the variation in impacts of predators on food web structure and dynamics encountered in natural systems, especially as system characteristics change (e.g., due to eutrophication). The strong contingencies in expression of, and the interactions between, TMIIs and DMIIs suggest that simple comparisons of the relative importance of different types of indirect effects across systems will be of limited value without attention to context. Finally, it is important to distinguish between DMIIs and TMIIs not only because these indirect effects can have different or opposing consequences, but because they may be transmitted through different routes in the food web. Clearly the effects of predators can be far more inter- esting than often portrayed, and hopefully exploring these effects will improve our ability to more accurately predict the impacts of predators.

\section{ACKNOWLEDGMENTS}

We thank Mara Zimmerman, Kyla Boyse, Alexandra Minn, and Josh Van Buskirk for assistance in the field, and M. Zimmerman for performing the statistical analysis. We also thank Elizabeth Fejes for conducting the periphyton species counts; Norman Andresen, Kalina Manoylov, and Jan Stevenson for help with species identification; Trent Malcolm for conducting the chlorophyll $a$ analysis; and Danielle Cholewiak for analysis of the snail samples. We also thank Barbara Downs and an anonymous reviewer for helpful comments on an earlier version of the manuscript. This research was supported by NSF grants DEB-9615523 and DEB0089809 to E. Werner and S. Peacor and support from the Michigan Agricultural Experimental Station to S. D. Peacor. This is Great Lakes Environmental Research Laboratory contribution number 1356.

\section{Literature Cited}

Abrams, P. A. 1992. Predators that benefit prey and prey that harm predators - unusual effects of interacting foraging adaptations. American Naturalist 140:573-600.

Abrams, P. A. 1995. Implications of dynamically variable traits for identifying, classifying, and measuring direct and indirect effects in ecological communities. American Naturalist 146:112-134.

Abrams, P. A., B. A. Menge, G. G. Mittelbach, D. Spiller, and P. Yodzis. 1996. The role of indirect effects in food webs. Pages 371-395 in G. A. Polis and K. O. Winemiller, editors. Food webs: integration of patterns and dynamics. Chapman and Hall, New York, New York, USA.

Bolker, B., M. Holyoak, V. Krivan, L. Rowe, and O. Schmitz. 2003. Connecting theoretical and empirical studies of traitmediated interactions. Ecology 84:1101-1114.

Brönmark, C., S. P. Klosiewski, and R. A. Stein. 1992. Indirect effects of predation in a freshwater, benthic food chain. Ecology 73:1662-1674.

Chase, J. M., W. Wilson, and S. Richards. 2001 Foraging trade-offs and resource patchiness: theory and experiments with a freshwater snail community. Ecology Letters 4:304312.

Dudley, T. L. 1992. Beneficial-effects of herbivores on stream macroalgae via epiphyte removal. Oikos 65:121-127.

Graham, M. D., and R. D. Vinebrooke. 1998. Trade-offs between herbivore resistance and competitiveness in periphyton of acidified lakes. Canadian Journal of Fisheries and Aquatic Sciences 55:806-814.

Huang, C. F., and A. Sih. 1991. An experimental study on the effects of salamander larvae on isopods in stream pools. Freshwater Biology 25:451-459.

Ives, A. R., and A. P. Dobson. 1987. Antipredator behavior and the population dynamics of simple predator-prey systems. American Naturalist 130:431-447.

Jenssen, T. A. 1967. Food habits of green frog Rana clamitans before and during metamorphosis. Copeia 1967:214-218.

Kupferberg, S. J., J. C. Marks, and M. E. Power. 1994. Effects of variation in natural algal and detrital diets on larval anuran (Hyla regilla) life-history traits. Copeia 1994:446457.

Lima, S. L. 1998. Nonlethal effects in the ecology of predator-prey interactions: what are the ecological effects of anti-predator decision-making? BioScience 48:25-34.

McCormick, P. V., and R. J. Stevenson. 1991. Mechanisms of benthic algal succession in lotic environments. Ecology 72:1835-1848. 
Noy-Meir, I. 1975. Stability of grazing systems: an application of predator-prey graphs. Journal of Ecology 63:459483.

Peacor, S. D. 2002. Positive effect of predators on prey growth rate through induced modifications of prey behaviour. Ecology Letters 5:77-85.

Peacor, S. D., and E. E. Werner. 2000. Predator effects on an assemblage of consumers through induced changes in consumer foraging behavior. Ecology 81:1998-2010.

Peacor, S. D., and E. E. Werner. 2001. The contribution of trait-mediated indirect effects to the net effects of a predator. Proceedings of the National Academy of Sciences (USA) 98:3904-3908.

Peacor, S. D., and E. E. Werner. 2004a. Context dependence of nonlethal predator effects on prey growth. Israel Journal of Zoology 50:139-167.

Peacor, S. D., and E. E. Werner. 2004b. How dependent are species-pair interaction strengths on other species in the food web? Ecology 85:2754-2763.

Polis, G. A., and K. O. Winemiller. 1996. Food webs: integration of patterns and dynamics. Chapman and Hall, New York, New York, USA.

Relyea, R. A. 2001. Morphological and behavioral plasticity of larval anurans in response to different predators. Ecology 82:523-540.

Relyea, R. A. 2004. Fine-tuned phenotypes: tadpole plasticity under 16 combinations of predators and competitors. Ecology 85:172-179.

Relyea, R. A., and E. E. Werner. 1999. Quantifying the relation between predator-induced behavior and growth performance in larval anurans. Ecology 80:2117-2124.

Resetarits, W. J. 2001. Colonization under threat of predation: avoidance of fish by an aquatic beetle, Tropisternus lateralis (Coleoptera: Hydrophilidae). Oecologia 129:155-160.

Rieger, J. F., C. A. Binckley, and W. J. Resetarits. 2004. Larval performance and oviposition site preference along a predation gradient. Ecology 85:2094-2099.

Rosemond, A. D. 1996. Indirect effects of herbivores modify predicted effects of resources and consumption on plant biomass. Pages 149-159 in G. A. Polis and K. O. Winemiller, editors. Food webs: integration of patterns and dynamics. Chapman and Hall, New York, New York, USA.

Sarnelle, O., K. W. Kratz, and S. D. Cooper. 1993. Effects of an invertebrate grazer on the spatial arrangement of a benthic microhabitat. Oecologia 96:208-218.

Schmitz, O. J., V. Krivan, and O. Ovadia. 2004. Trophic cascades: the primacy of trait-mediated indirect interactions. Ecology Letters 7:153-163.
Speziale, B. J., S. P. Schreiner, P. A. Giammatteo, and J. E. Schindler. 1984. Comparison of N,N-dimethylformamide, dimethylsulfoxide, and acetone for extraction of phytoplankton chlorophyll. Canadian Journal of Fisheries and Aquatic Sciences 41:1519-1522.

St. Amand, A. L. 1990. Mechanisms controlling metalimnetic communities and the importance of metalimnetic phytoplankton to whole lake primary productivity. Dissertation. University of Notre Dame, South Bend, Indiana, USA.

Steinman, A. D. 1996. Effects of grazers on freshwater benthic algae. Pages 341-373 in R. J. Stevenson, M. L. Bothwell, and R. L. Lowe, editors. Algal ecology: freshwater benthic ecosystems. Academic Press, San Diego, California, USA.

Strickland, J. D. H., and T. R. Parsons. 1972. A manual of seawater analysis. Second edition. Fisheries Research Board of Canada, Ottawa, Canada.

Turner, A. M. 2004. Non-lethal effects of predators on prey growth rates depend on prey density and nutrient additions. Oikos 104:561-569.

Turner, A. M., and G. G. Mittelbach. 1990. Predator avoidance and community structure: interactions among piscivores, planktivores, and plankton. Ecology 71:2241-2254.

Van Buskirk, J. 2000. The costs of an inducible defense in anuran larvae. Ecology 81:2813-2821.

Van Buskirk, J., and M. Arioli. 2002. Dosage response of an induced defense: how sensitive are tadpoles to predation risk? Ecology 83:1580-1585.

Van Buskirk, J., and K. L. Yurewicz. 1998. Effects of predators on prey growth rate: relative contributions of thinning and reduced activity. Oikos 82:20-28.

Werner, E. E., and B. R. Anholt. 1993. Ecological consequences of the trade-off between growth and mortality rates mediated by foraging activity. American Naturalist 142: 242-272.

Werner, E. E., and B. R. Anholt. 1996. Predator-induced behavioral indirect effects: consequences to competitive interactions in anuran larvae. Ecology 77:157-169.

Werner, E. E., and S. D. Peacor. 2003. A review of traitmediated indirect interactions in ecological communities. Ecology 84:1083-1100.

Wilbur, H. M. 1987. Regulation of structure in complex systems: experimental temporary pond communities. Ecology 68:1437-1452.

Yodzis, P. 1996. Food webs and perturbation experiments: theory and practice. Pages 192-200 in G. A. Polis and K. O. Winemiller, editors. Food webs: integration of patterns and dynamics. Chapman and Hall, New York, New York, USA. 